\title{
Noise Reduction of an Axial Piston Pump by Valve Plate Optimization
}

\author{
Shao-Gan Ye ${ }^{1,2}$, Jun-Hui Zhang ${ }^{1 *}$ and Bing $X u^{1}$
}

\begin{abstract}
Current researches mainly focus on the investigations of the valve plate utilizing pressure relief grooves. However, air-release and cavitation can occur near the grooves. The valve plate utilizing damping holes show excellent performance in avoiding air-release and cavitation. This study aims to reduce the noise emitted from an axial piston pump using a novel valve plate utilizing damping holes. A dynamic pump model is developed, in which the fluid properties are carefully modeled to capture the phenomena of air release and cavitation. The causes of different noise sources are investigated using the model. A comprehensive parametric analysis is conducted to enhance the understanding of the effects of the valve plate parameters on the noise sources. A multi-objective genetic algorithm optimization method is proposed to optimize the parameters of valve plate. The amplitudes of the swash plate moment and flow rates in the inlet and outlet ports are defined as the objective functions. The pressure overshoot and undershoot in the piston chamber are limited by properly constraining the highest and lowest pressure values. A comparison of the various noise sources between the original and optimized designs over a wide range of pressure levels shows that the noise sources are reduced at high pressures. The results of the sound pressure level measurements show that the optimized valve plate reduces the noise level by $1.6 \mathrm{~dB}(\mathrm{~A})$ at the rated working condition. The proposed method is effective in reducing the noise of axial piston pumps and contributes to the development of quieter axial piston machines.
\end{abstract}

Keywords: Axial piston pump, Noise reduction, Fluid-borne noise, Structure-borne noise, Parametric analysis, Multiobjective optimization

\section{Introduction}

Axial piston pumps are broadly applied in industrial and mobile applications to convert mechanical energy into fluid power energy [1]. Axial piston pumps are advantageous in terms of their efficiency, compactness and reliability $[2,3]$. The prominent disadvantage is a high noise level. The noise emitted from an axial piston pump can be divided into structure-borne noise, fluid-borne noise and airborne noise [4]. The structure-borne noise is generated by various internal forces and moments, and the fluid-borne noise is produced by flow ripples in the inlet and outlet ports [5]. Both structure-borne noise and fluidborne noise contribute to the generation of airborne noise.

For an axial piston pump, the valve plate is the main component affecting the noise generation, especially

\footnotetext{
*Correspondence: benzjh@zju.edu.cn

1 State Key Laboratory of Fluid Power and Mechatronics Systems,

Zhejiang University, Hangzhou 310027, China

Full list of author information is available at the end of the article
}

the transition regions between the outlet and inlet ports. In many industrial applications, the pressure relief grooves are machined in the transition regions to smooth the piston chamber pressure. It is desirable to find the optimum type of pressure relief groove of those that can be manufactured. The effects of different types of cross-sectional grooves on the piston chamber pressure were investigated, and the results showed that a steeply sloping triangular cross-sectional groove was the optimal design to reduce the pressure overshoot in the piston chamber [6]. Three different types of slot geometries were compared considering their effects on the pressure transient in the piston chamber, and the results indicated that the quadratic varying slot geometry had no clear advantages compared with the constant and linearly varying slot geometries [7]. In addition to the type of pressure relief groove, the groove volume, slope and angular extent of the pressure relief groove also have great 
effects on the pressure ripple [8]. The optimal match between the pre-compression angle and cylinderkidney angle was determined based on a parametric analysis at one particular operating pressure level to maximize the outlet flow rate and minimize the pressure ripple [9]. The valve plate parameters were found to affect the volumetric efficiency, fluid-borne noise sources, structure-borne noise sources and control characteristics of an axial piston pump [10, 11], and a multi-objective optimization method using genetic algorithm was proposed to optimize the parameters of valve plate [12-14]. The valve plate's effect on the volumetric efficiency and pressure pulsations of an asymmetric axial piston pump was investigated [15], and the valve plate was designed for a dual-acting axial piston pump [16].

In addition to the valve plate that utilizes pressure relief grooves in the transition regions, the valve plate that utilizes damping holes in the transition regions also exhibits several unique advantages, such as avoiding air-release and cavitation [17], which is crucial for the good performance of an axial piston pump. However, this type of valve plate has not been widely investigated. In this study, a valve plate utilizing two damping holes (directly linked to the outlet port) in the transition region from the inlet port to the outlet port and one damping hole (directly linked to the pump case) in the transition region from the outlet port to the inlet port is investigated. The remainder of this paper includes the following:

1. A dynamic pump model is developed, in which the fluid properties are carefully modeled to reflect the phenomena of air-release and cavitation.

2. The causes of and factors affecting the noise sources are identified based on the pump model.

3. A comprehensive parametric analysis is conducted to analyze the effects of the valve plate parameters on the generation of noise sources.

4. A multi-objective optimization method using a genetic algorithm is proposed to optimize the valve plate parameters.

It will be shown that the noise sources and noise level can be reduced at high pressure levels by a comparison between the original and optimized valve plates, and the noise level is reduced by $1.6 \mathrm{~dB}(\mathrm{~A})$ at the rated working condition.

\section{Pump Modeling}

\subsection{Description of the Pump}

The investigated swash plate axial piston pump utilizes nine pistons as shown in Figure 1. For simplicity, only one piston is shown, and the control piston used to regulate the displacement of the pump is not shown. At normal operating conditions, the shaft and cylinder rotate at a constant speed. Because the swash plate plane inclines, the piston executes sinusoidal motion along the $x$ direction. The piston discharges fluid to the outlet as it advances into the piston chamber, and it sucks fluid into the piston chamber as it draws back from the piston chamber. This process enables the fundamental task of fluid power transmission.

A loud noise is emitted by the pump from different noise sources, and the leakages across different friction interfaces, i.e., the piston/cylinder interfaces, slipper/ swash-plate interfaces and cylinder/valve-plate interface, have impacts on the noise sources because the pressure build-up in the piston chamber depends on them [18]. To fully capture the leakages across the friction pairs, special effort is required for the modeling of the piston/cylinder interfaces $[19,20]$, slipper/swash-plate interfaces [21, 22], and cylinder/valve-plate interface [23]. However, the classical analytical equations used to describe the leakages are acceptable because they are easier and faster to solve [24].

\subsection{Valve Plate}

Figure 2 shows the geometry of the valve plate used in this study. Although damping holes one and two both directly link to the outlet port, their functions differ from each other. The function of the first damping hole is to supply fluid to the piston chamber to avoid cavitation when the piston chamber disconnects to the inlet port. The function of the second damping hole is to make the pressure in the piston chamber increase faster to avoid the sudden flow reduction that occurs when the piston chamber connects to the outlet port by providing extra fluid to the piston chamber.

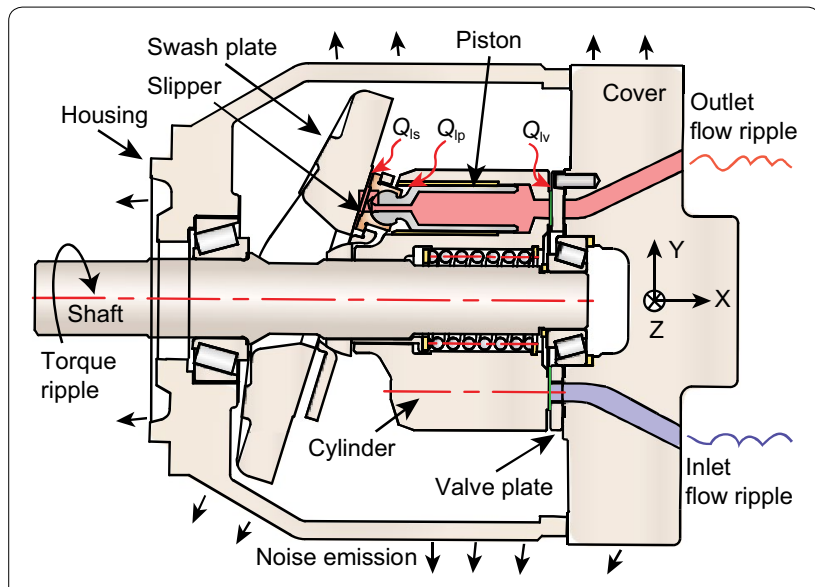

Figure 1 Diagram of the axial piston pump 


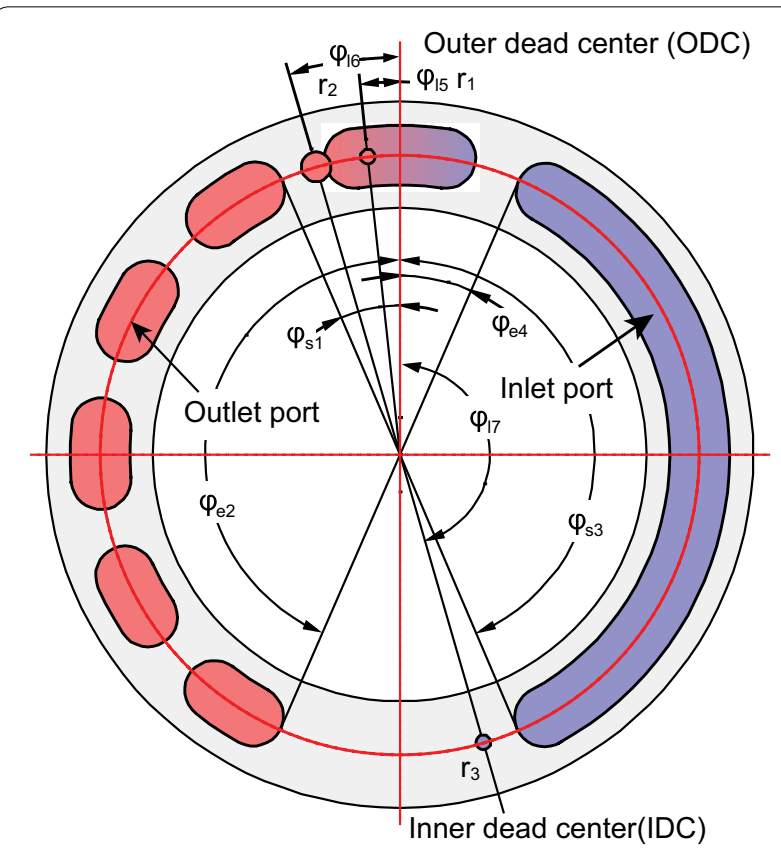

Figure 2 Valve plate geometry

Damping hole three does not connect with the inlet port but instead links directly to the pump case. This design reduces the pressure in the piston chamber by bleeding off a small amount of fluid directly to the pump case. In many cases, air is released from the oil when the piston chamber pressure falls below the saturation pressure. With ordinary valve plate design using a pressure relief groove in the transition regions, the released air is stored in the piston chamber. In contrast, air is released directly into the pump case which enables the released air to dissolve into the fluid [17].
The valve plate influences the pumping dynamics by controlling the communication areas between the piston chamber and the inlet and outlet ports. The communication areas are calculated by piecewise functions according to the relative position of the piston chamber to the ports as shown in Figure 3(a), and the communication areas are divided into seven segments as expressed by:

$$
A= \begin{cases}0 & 0<\theta<\theta_{1} \\ r_{k}^{2}\left(2 \varphi_{1}-\sin \left(2 \varphi_{1}\right)\right) & \theta_{1}<\theta<\theta_{2} \\ \pi r_{k}^{2}+2 r_{k}\left(\theta-\theta_{2}\right) R & \theta_{2}<\theta<\theta_{3} \\ \pi r_{k}^{2}+2 r_{k} l_{k} & \theta_{3}<\theta<\theta_{4} \\ \pi r_{k}^{2}+2 r_{k}\left(\theta-\theta_{4}\right) R & \theta_{4}<\theta<\theta_{5} \\ r_{k}^{2}\left(2 \varphi_{2}-\sin \left(2 \varphi_{2}\right)\right) & \theta_{5}<\theta<\theta_{6} \\ 0 & \theta_{6}<\theta<2 \pi\end{cases}
$$

where $r_{k}$ is the radius of the cylinder port, $l_{k}$ is the linearized length of the cylinder port, and $\varphi_{1}$ and $\varphi_{2}$ are functions of $\theta$, as described in Guan et al. [25]. $\theta_{1}, \theta_{2}, \theta_{3}, \theta_{4}, \theta_{5}$ and $\theta_{6}$ can be easily calculated based on the starting and ending locations of the inlet and outlet ports $\left(\varphi_{\mathrm{s} 1}, \varphi_{\mathrm{e} 2}, \varphi_{\mathrm{s} 3}\right.$ and $\left.\varphi_{\mathrm{e} 4}\right)$ by referencing to Figure 3(a).

Similarly, the communication areas between the piston chamber and damping holes are divided into five segments, as shown in Figure 3(b), and as expressed by:

$$
A= \begin{cases}0 & 0<\theta<\alpha_{1} \\ r_{h}^{2}\left(\varphi_{3}-\frac{1}{2} \sin \varphi_{3}\right)+r_{k}^{2}\left(\varphi_{4}-\frac{1}{2} \sin \varphi_{4}\right) & \alpha_{1}<\theta<\alpha_{2} \\ \pi r_{h}^{2} & \alpha_{2}<\theta<\alpha_{3} \\ r_{h}^{2}\left(\varphi_{5}-\frac{1}{2} \sin \varphi_{5}\right)+r_{k}^{2}\left(\varphi_{6}-\frac{1}{2} \sin \varphi_{6}\right) & \alpha_{3}<\theta<\alpha_{4} \\ 0 & \alpha_{4}<\theta<2 \pi\end{cases}
$$

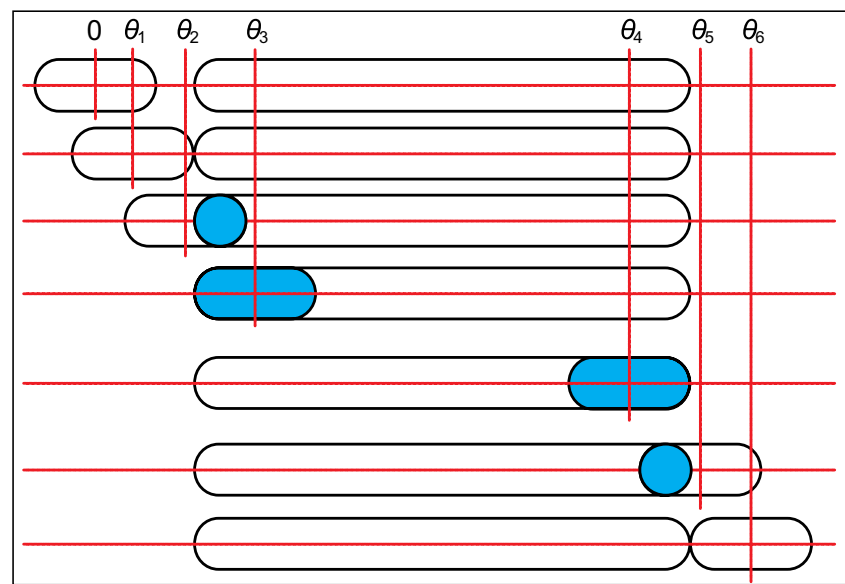

a between the piston chamber and inet and outlet ports

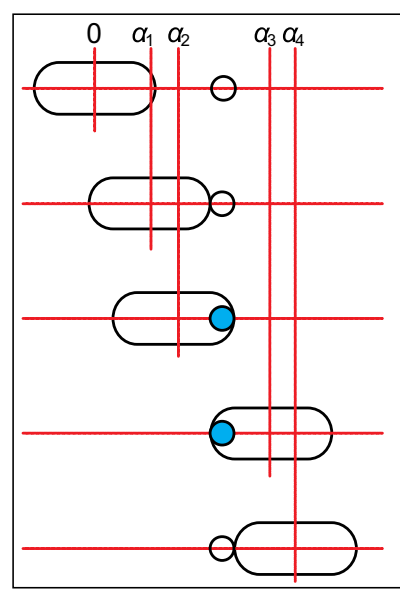

b between the piston chamber and damping hole

Figure 3 Schematic diagram shows the variations in the communication area 
where $r_{h}$ is the radius of the damping hole, $\varphi_{3}, \varphi_{4}, \varphi_{5}$ and $\varphi_{6}$ are functions of $\theta$, as described in Guan et al. [25]. $\alpha_{1}$, $\alpha_{2}, \alpha_{3}$ and $\alpha_{4}$ can also be easily calculated based on the starting and ending locations of the damping holes $\left(\varphi_{15}\right.$, $\varphi_{16}$ and $\left.\varphi_{17}\right)$ and the radii of the damping holes $\left(r_{1}, r_{2}\right.$ and $\left.r_{3}\right)$ by referencing to Figure 3(b).

\subsection{Dynamic Model}

The instantaneous pressure in the piston chamber is determined by applying continuity equation in integral form [26], as expressed as:

$$
\frac{\mathrm{d} p_{\mathrm{i}}}{\mathrm{d} t}=\frac{\beta_{\mathrm{e}}}{V_{\mathrm{pci}}}\left(Q_{\mathrm{lpi}}-Q_{\mathrm{hpi}}-Q_{\mathrm{li}}-\frac{\mathrm{d} V_{\mathrm{pci}}}{\mathrm{d} t}\right)
$$

where $\beta_{\mathrm{e}}$ is the bulk modulus of the hydraulic oil, $V_{\mathrm{pci}}$ is the fluid volume in the piston chamber, $Q_{\mathrm{lpi}}$ and $Q_{\mathrm{hpi}}$ are the flow rates between the piston chamber and the inlet and outlet ports, respectively, and $Q_{\mathrm{li}}$ is the leakages across different friction pairs.

The flow rates between the piston chamber and the inlet and outlet ports are expressed as

$$
\begin{aligned}
& Q_{\text {lpi }}=C A_{\text {lpi }} \sqrt{\frac{2\left|p_{\mathrm{i}}-p_{\mathrm{l}}\right|}{\rho}} \cdot \operatorname{sign}\left(p_{\mathrm{i}}-p_{\mathrm{l}}\right) \\
& Q_{\mathrm{hpi}}=C A_{\mathrm{hpi}} \sqrt{\frac{2\left|p_{\mathrm{h}}-p_{\mathrm{i}}\right|}{\rho}} \cdot \operatorname{sign}\left(p_{\mathrm{h}}-p_{\mathrm{i}}\right)
\end{aligned}
$$

where $C$ is the flow coefficient, $p_{\mathrm{l}}$ and $p_{\mathrm{h}}$ are the pressures in the inlet and outlet ports, respectively, $A_{\mathrm{lpi}}$ and $A_{\mathrm{hpi}}$ are the communication areas between the piston chamber and the inlet and outlet ports, respectively, and $\rho$ is the density of the hydraulic oil.
The volume in the piston chamber varies with the location of the piston, which is expressed as:

$$
V_{\mathrm{pci}}=V_{0}-\frac{\pi}{4} d_{\mathrm{p}}^{2} R \tan \beta \cos \theta_{\mathrm{i}}
$$

where $V_{0}$ is the fluid volume of the piston chamber in the outer dead center (ODC), $d_{\mathrm{p}}$ is the piston diameter, $R$ is the distribution radius of the piston hole, $\beta$ is the swash plate inclination angle, $\theta_{\mathrm{i}}$ is the rotational angle.

\subsection{Fluid Properties}

The accurate calculation of the fluid properties is essential for the modeling of an axial piston pump, especially when the pressure is low [27]. In real hydraulic systems, the hydraulic oil contains air that is dissolved in the fluid or is free in the form of bubbles, depending on the pressure and temperature of the hydraulic oil. Adequate modeling of the hydraulic oil can accurate capture the phenomena of air-release and cavitation, which is critical to the design of a quieter axial piston pump [28]. In this study, the fluid model is developed considering the airrelease and vapor cavitation, in which different types of mixtures of the hydraulic oil are defined according to the variation of the pressure. There is no vapor if the pressure is larger than the saturation pressure $\left(p_{\text {sat }}\right)$, whereas the oil starts to boil if the pressure is smaller than the saturation pressure. The boiling occurs over a wide pressure range because the fluid is a mixture. Thus, the pressure at which cavitation starts is defined as the high saturated vapor pressure $\left(p_{\mathrm{VAPH}}\right)$, and the pressure at which cavitation occurs completely is defined as the low saturated vapor pressure $\left(p_{\mathrm{VAPL}}\right)$ [28]. As the pressure becomes lower than the low saturated vapor pressure, all of the liquid is vaporized, and there is only vapor and air. In line with the assumptions, the fluid density is defined as

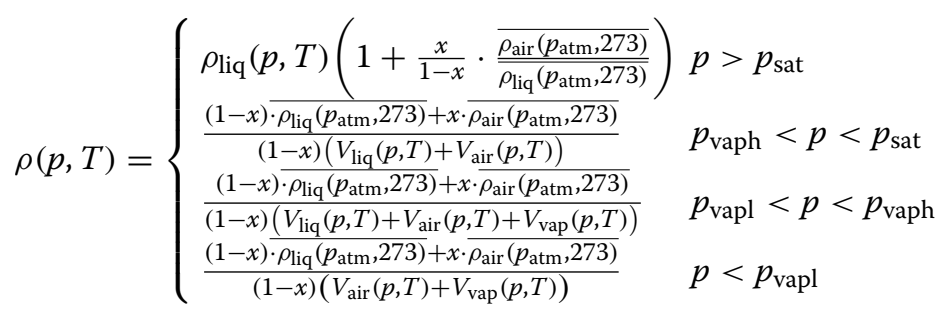


The detail description of the parameters in determining the density of the hydraulic oil can be found in Ref. [29]. And the bulk modulus of the hydraulic oil is expressed as [29]

$$
\beta_{e}(p, T)=\rho(p, T) \cdot \frac{d p(p, T)}{d \rho(p, T)}
$$

\section{Generation of Noise}

To understand the generation of noise from different sources in the axial piston pump, it is desirable to identify the factors contributing to the generation of flow ripples in the inlet and outlet ports and the fluctuation of the swash plate moment.

The flow rates in the inlet and outlet ports are calculated by summing the flow rates from all of the piston chambers as:

$$
\begin{aligned}
& Q_{\mathrm{LP}}=\sum_{\mathrm{i}=1}^{Z} Q_{\mathrm{lpi}} \\
& Q_{\mathrm{HP}}=\sum_{\mathrm{i}=1}^{Z} Q_{\mathrm{hpi}}
\end{aligned}
$$

At normal operating conditions, the inertia forces and frictional forces are far smaller than the pressure forces. The swash plate moment can be calculated by summing all of the forces acting on the swash plate generated by the prominent piston pressure forces, as given by

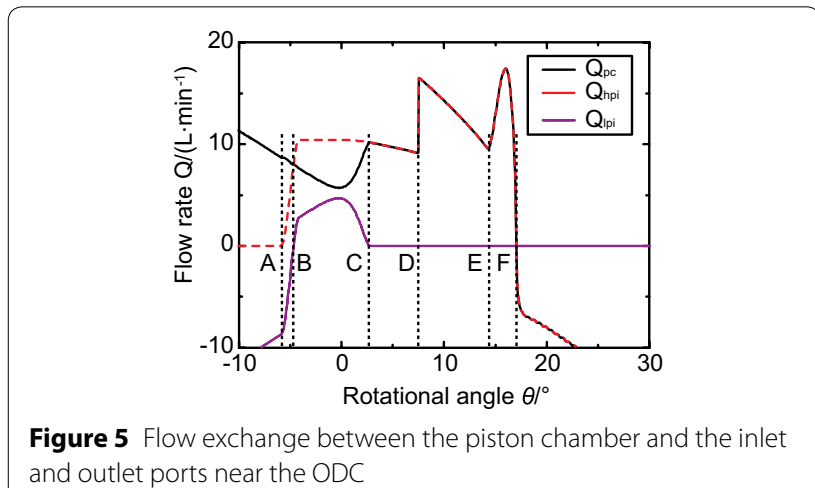

$$
M_{\mathrm{z}}=\frac{\pi}{4} d_{\mathrm{p}}^{2} \cdot \frac{R}{\cos ^{2} \beta} \sum_{\mathrm{i}=1}^{Z} p_{\mathrm{i}} \cos \theta_{\mathrm{i}}
$$

where $Z$ is the total number of pistons, $p_{\mathrm{i}}$ is the piston chamber pressure.

\subsection{Outlet Flow Rate}

Figure 4 shows the schematic diagram of the flow entering and leaving the piston chamber near the ODC, which can be divided into seven stages. At the first stage (Figure 4(a)), the piston chamber sucks fluid from the inlet port before the piston reaches point A (Figure 5) $\left(Q_{\mathrm{pc}}=Q_{\mathrm{lpi}}\right)$. The piston chamber pressure decreases when the provided fluid is less than that required because the communication area between the inlet port and piston chamber decreases. At the second stage (from points

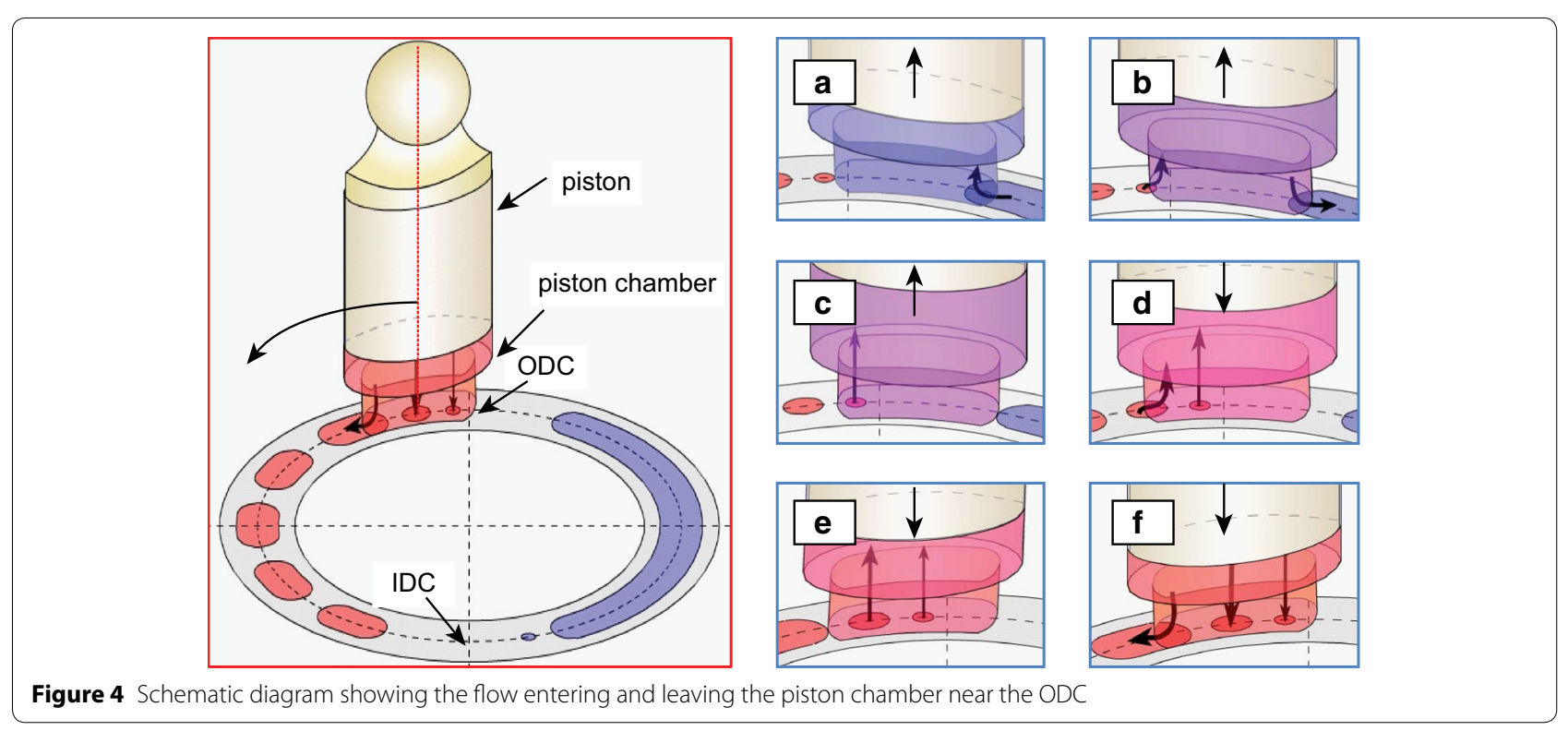


A to B), damping hole one is open to the piston chamber, and fluid from the outlet port $\left(Q_{\mathrm{hpi}}\right)$ enters into the piston chamber (Figure 4(b)). Therefore, the piston chamber pressure increases, and the pressure difference between the inlet port and piston chamber decreases, which makes the flow rate between the inlet port and piston chamber $\left(Q_{\mathrm{lpi}}\right)$ decrease. When the piston chamber pressure becomes equal to the inlet pressure at point $B$, the flow rate between the inlet port and piston chamber $\left(Q_{l p i}\right)$ becomes zero. At the third stage (from points B to $C)$, the piston chamber pressure is larger than the inlet pressure, and fluid enters into the inlet port. During this stage, the pressure difference between the piston chamber and inlet port increases, whereas the communication area decreases. This makes the flow rate first increase and then decrease. At point $\mathrm{C}$, the communication area between the piston chamber and inlet port becomes zero (Figure $4(\mathrm{c}))$, and the flow rate $\left(Q_{\mathrm{lpi}}\right)$ becomes zero. At point $\mathrm{D}$, damping hole two starts open to the piston chamber (Figure 4(d)), which increases the communication area between the piston chamber and outlet port, making the pressure in the piston chamber increase more rapidly. At point $\mathrm{E}$, the piston chamber starts to connect to the outlet port (Figure 4(e)), and the communication area becomes larger. At point $F$, the piston chamber

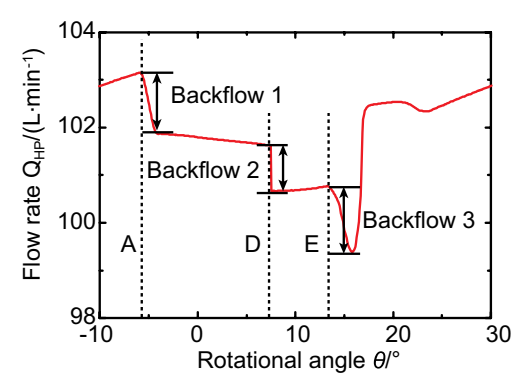

Figure 6 Flow rate in the outlet port pressure is equal to the outlet pressure, and the piston starts discharging fluid to the outlet port (Figure 4(f)).

Figure 6 shows the variation in the outlet flow rate. The flow rate decreases rapidly when the piston chamber is connecting with damping hole one at point $\mathrm{A}$. The sharp decrease (backflow 1) ends when the damping hole is fully open, after which the flow rate decreases smoothly because the pressure difference between the outlet port and piston chamber decreases. When the piston chamber is connected with damping hole two at point $\mathrm{D}$, the communication area between the outlet port and piston chamber increases more rapidly, and the flow rate decreases (backflow 2) sharply again. At point E, the piston chamber is connected with the outlet port, and the outlet flow rate further decreases (backflow 3) because the outlet pressure is still larger than the piston chamber pressure.

\subsection{Inlet Flow Rate}

Figure 7 shows the schematic diagram of the flow entering and leaving the piston chamber near the inner dead center (IDC), which can be divided into four stages. In the first stage, the piston chamber does not connect with damping hole three before point G (Figure 7(a)), and the flow rate between the piston chamber and damping hole $\left(Q_{c}\right)$ is zero. In the second stage, the piston chamber starts to connect with the damping hole (Figure 7(b)), and the fluid in the piston chamber $\left(Q_{p c}\right)$ begins to enter the pump case through the damping hole because the pressure difference between the piston chamber and pump case is large. In the third stage, the piston chamber connects to the inlet port (Figure $7(\mathrm{c})$ ). The communication area between the piston chamber and inlet port increases rapidly, and the amount of fluid entering into the inlet port $\left(Q_{\mathrm{lpi}}\right)$ is large, making the piston chamber pressure decrease rapidly. The piston chamber pressure decreases to the inlet pressure at point I (Figure 7(d)), at which the piston starts to suck fluid from the inlet port.
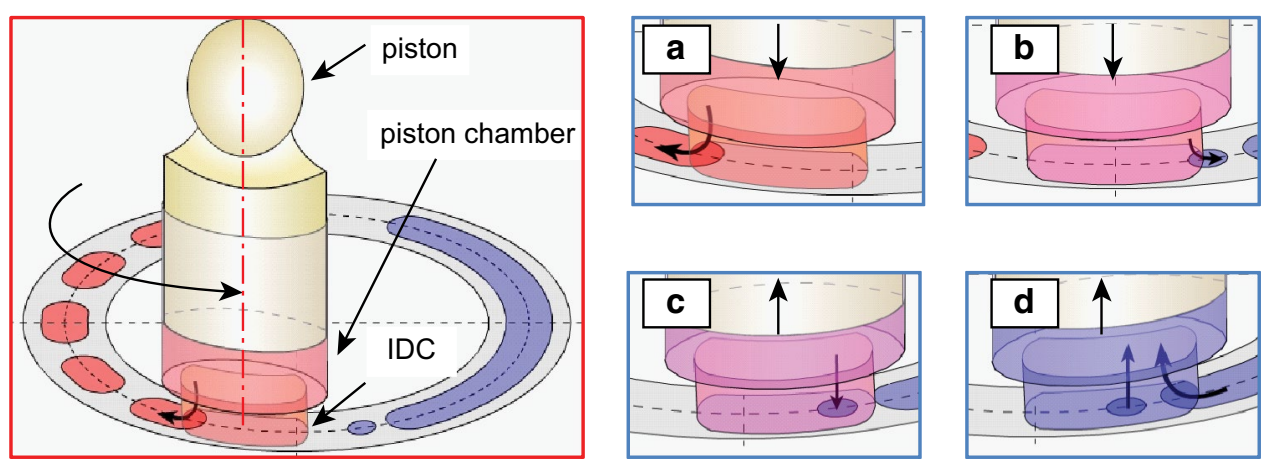

Figure 7 Schematic diagram showing the flow entering and leaving the piston chamber near the IDC 


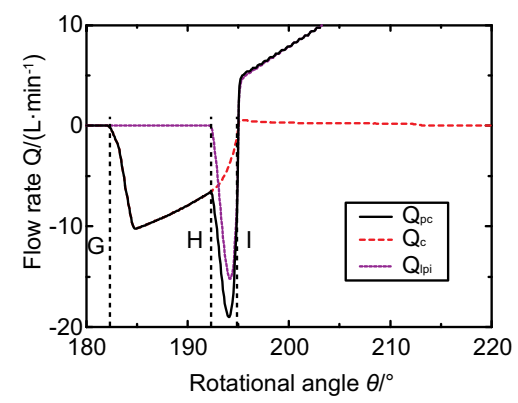

Figure 8 Variations in the flow rate near the IDC

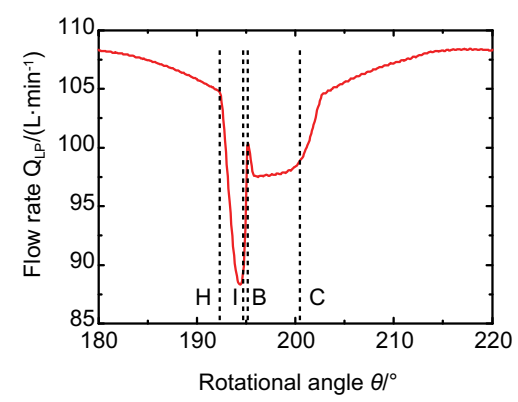

Figure 9 Flow rate in the inlet port

Figure 8 shows the variation in the inlet flow rate. The inlet flow rate decreases rapidly when the piston chamber is connected with the inlet port at point $\mathrm{H}$, as shown in Figure 9. The fluid stops entering into the inlet port when the piston chamber is equal to the inlet pressure at point I. This is one cause of the inlet flow ripple; the other is the fluid entering from the outlet port into the inlet port when they connect with each other by the piston chamber near the ODC, as shown in Figure 5 (from points B $(195.28=-4.72+40 \times 5)$ to $\mathrm{C}(202.58=2.58+40 \times 5))$.

\subsection{Swash Plate Moment}

Figure 10 shows the variations in the piston chamber pressure, $p_{\mathrm{i}}$, and the swash plate moment, $M_{\mathrm{z}}$. The piston chamber pressure is larger than zero during a period of $360^{\circ}$. The swash plate moment has four peaks, two maximum and minimum values in a circle. The amplitude of the swash plate moment is determined by the peaks. The four peaks occur at the points at which the piston chamber pressure starts to increase, equals the outlet pressure, starts to decrease and equals the inlet pressure. As shown in Figure 10(b), the first maximum swash plate moment occurs when one piston chamber reaches point I $(-5.00=195.00-40 \times 5)$, and the swash plate moment decreases after point I. The first minimum value occurs when one piston chamber reaches point A (7.46),
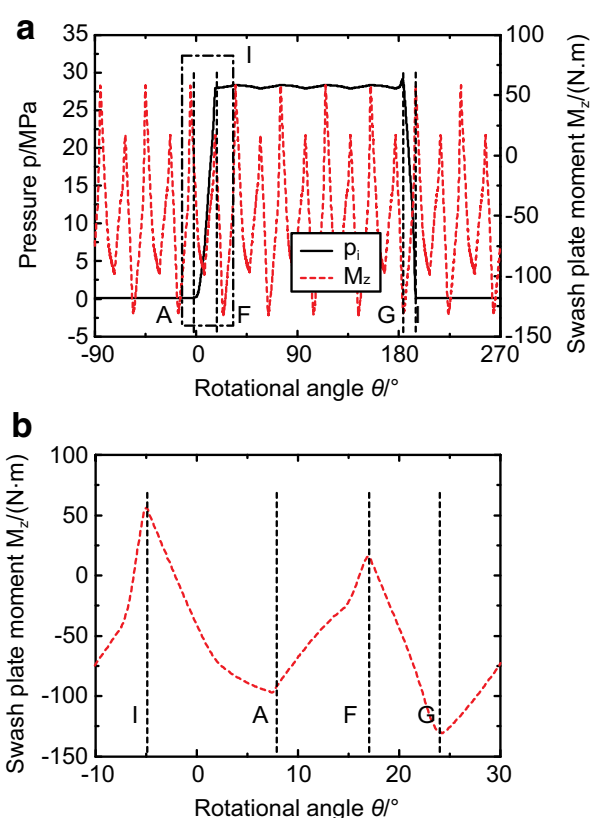

Figure 10 Piston chamber pressure and swash plate moment

after which the swash plate moment begins to increase because the piston chamber pressure increases. Then, the swash plate moment increases to its second maximum value when the moment generated by the piston (near the ODC) reaches its maximum at point F (17.00). After that position, the swash plate moment starts to decrease because the moment generated by the piston (near the IDC) decreases, and the swash plate moment decreases to the second minimum value at point $G$ $(24.48=184.48-40 \times 4)$ when the moment generated by the piston reaches its minimum value.

These analyses identify that the piston chamber pressure has a close relationship with the fluctuation of the swash plate moment, and the piston chamber pressure is determined by the flow exchanges between the piston chamber and inlet port, the outlet port and the pump case, which are greatly affected by the valve plate parameters.

\section{Parametric Study}

A comprehensive parametric analysis is conducted to enhance the understanding of the effects of the valve plate parameters on the pump noise sources. In the parametric analysis, when the effect of one parameter is investigated, the other parameters remain the same. The default values (original valve plate) of the parameters are shown in Table 1, and the optimized values obtained in Section 5 using multi-objective optimization method are also shown here. Special attention is paid on the effects 
Table 1 Values of the valve plate parameters

\begin{tabular}{lllr}
\hline Name of structure variable & Default value & Parameter range & Optimized value \\
\hline Starting location of outlet port $\varphi_{\mathrm{s} 1}\left({ }^{\circ}\right)$ & 21 & $18-30$ & 23.79 \\
Ending location of outlet port $\varphi_{\mathrm{e} 2}\left({ }^{\circ}\right)$ & 161 & $154-168$ & 157.53 \\
Starting location of inlet port $\varphi_{\mathrm{s} 3}\left(^{\circ}\right)$ & 161 & $154-168$ & 154.22 \\
Ending location of inlet port $\varphi_{\mathrm{e} 4}\left({ }^{\circ}\right)$ & 19 & $18-30$ & 26.11 \\
Location of damping hole one $\varphi_{15}\left({ }^{\circ}\right)$ & 2 & $1.8-2.2$ & 1.84 \\
Radius of damping hole one $r_{1}(\mathrm{~mm})$ & 0.55 & $0.3-0.7$ & 0.50 \\
Location of damping hole two $\varphi_{16}\left({ }^{\circ}\right)$ & 10.7 & $8-12$ & 10.26 \\
Radius of damping hole two $r_{2}(\mathrm{~mm})$ & 0.7 & $0.5-1$ & 0.72 \\
Location of damping hole three $\varphi_{17}\left({ }^{\circ}\right)$ & 169.3 & $168-172$ & 171.96 \\
Radius of damping hole three $r_{3}(\mathrm{~mm})$ & 0.55 & $0.3-0.7$ & 0.48 \\
\hline
\end{tabular}
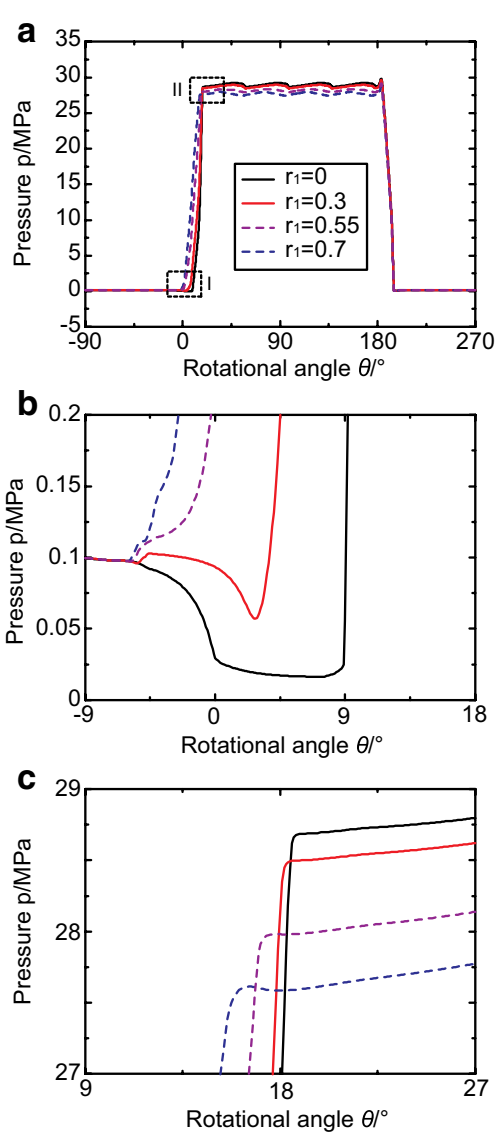

Figure 11 Effects of damping hole one on the piston chamber pressure

of the radii of the different damping holes on the piston chamber pressure, the outlet and inlet flow rates and the swash plate moment.

\subsection{Effects of Damping Hole One}

Figure 11 shows the effects of the radius of damping hole one, $r_{1}$, on the piston chamber pressure. The mean pressures in the piston chamber are different at different radii when the piston chamber connects to the outlet port. The outlet pressure is larger when the radius is smaller. Specifically, as shown in Figure 11(c), the pressures fluctuate around 28.7 and $27.5 \mathrm{MPa}$ when the radius is 0 and $0.7 \mathrm{~mm}$, respectively. This is because the effective flow rate is affected by the damping hole (Figure 12). The outlet flow rate starts to decrease near point A when the damping hole is employed, whereas it continues to increase near point $A$ when the radius is zero. The fluid (backflow 1) starts to enter the piston chamber from the outlet port when the piston chamber is connected with the damping hole. Backflow 1 is larger when the radius is larger, resulting in a smaller effective flow rate at a larger radius. Because a throttle valve is used to regulate the pressure in the outlet line, the outlet pressure is larger when the flow rate increases. In addition, the flow rate amplitude is smaller because the total backflow is smaller when the radius is larger (Figure 12). The main reason is that the pressure difference between the piston chamber and outlet port is smaller when the piston chamber pressure increases faster at point $\mathrm{E}$ (Figure 6).

Second, the radius of the damping hole affects the pressure undershoot, as shown in Figure 11(b). The lowest pressure increases when the radius increases. The lowest pressure is $0.017 \mathrm{MPa}$ when the damping hole is not used, and it increases to a value higher than $0.05 \mathrm{MPa}$ (high saturated vapor pressure) when the radius is $0.3 \mathrm{~mm}$. As the high saturated vapor pressure is $0.05 \mathrm{MPa}$, the cavitation occurs when the radius is too small. This implies that the damping hole is capable of maintaining a relatively higher lowest pressure at the 


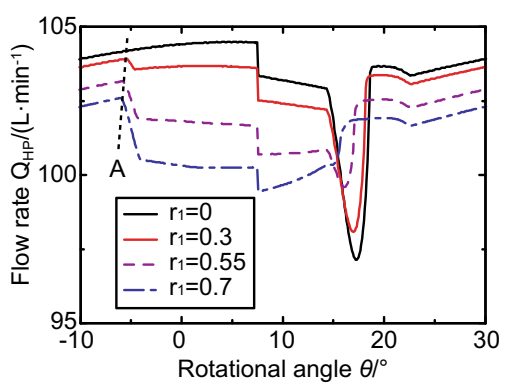

Figure 12 Effects of damping hole one on the outlet flow rate

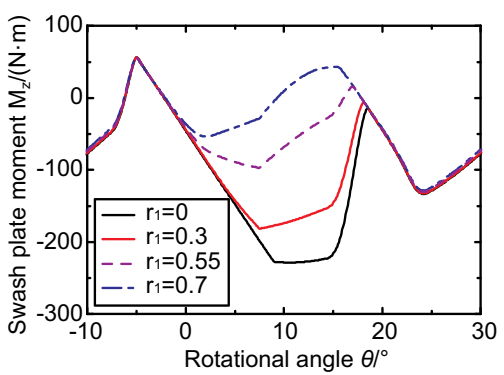

Figure 13 Effects of damping hole one on the swash plate moment

start of the compression process, which is the main reason for employing the damping hole.

Third, the rotational angles at which the pressure starts to increase and equals the outlet pressure are smaller when the radius is larger. This affects the first minimum and second maximum swash plate moments, as shown in Figure 13. The first minimum and second maximum swash plate moments are larger when the radius is larger. When $r_{1}<0.3$, the smallest swash plate moment is determined by the first minimum value, and as the radius increases, the second minimum becomes the smallest one, whereas the largest swash plate moment is the first maximum value. Thus, the amplitude of the swash plate moment is smaller at a larger radius when the first minimum swash plate moment is smaller than the second one, and the amplitude is nearly constant when the second minimum swash plate moment becomes smaller than the first one.

\subsection{Effects of Damping Hole Two}

The effects of the radius of damping hole two, $r_{2}$, on the piston chamber pressure are shown in Figure 14. The damping hole has no effect on the pressure at the start of the compression process. It mainly affects the rotational angle at which the piston chamber pressure equals the outlet pressure. As illustrated in Figure 14(b), the rotational angle is smaller when the radius is larger because
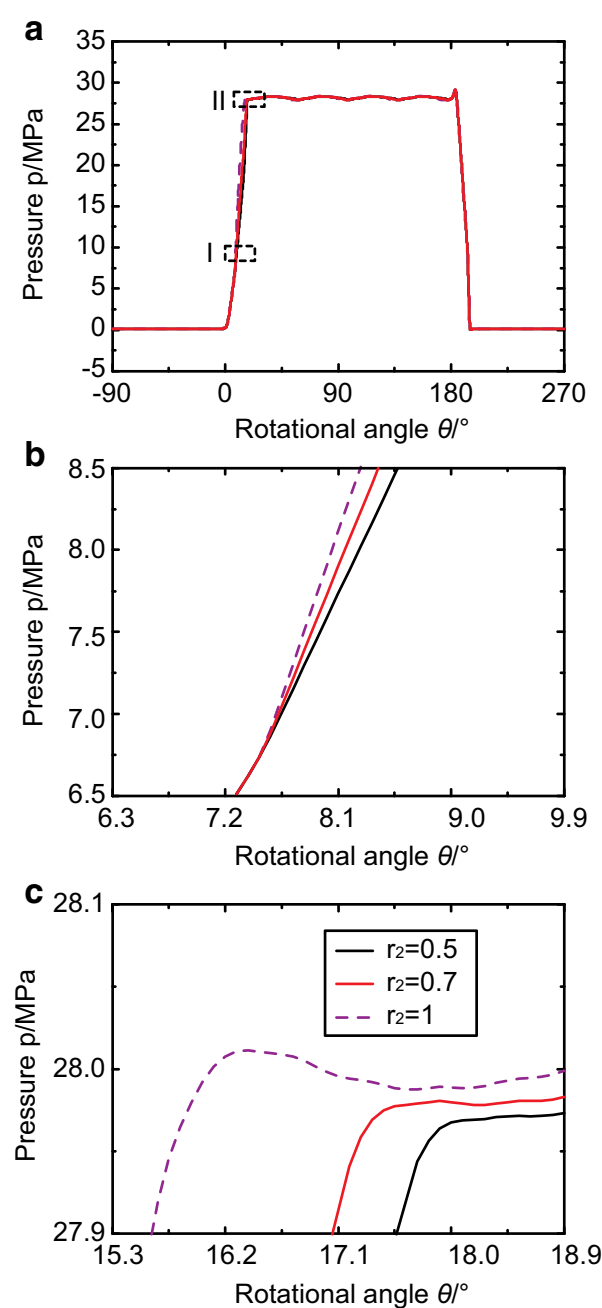

Figure 14 Effects of damping hole two on the piston chamber pressure

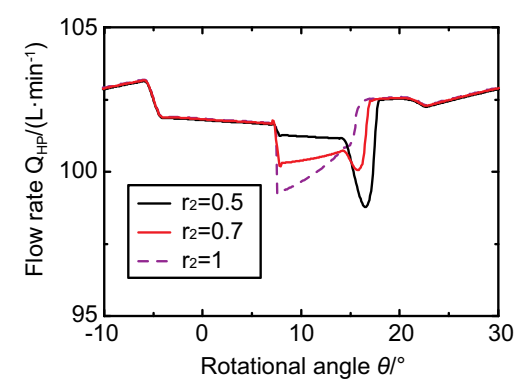

Figure 15 Effects of damping hole two on the outlet flow rate

when the radius is larger, a larger amount of backflow is generated from the outlet port into the piston chamber, which makes the piston chamber pressure increase faster. Additionally, the piston chamber is compressed 
earlier when the radius is larger, and the piston chamber pressure increases faster when the damping hole is larger. This affects the outlet flow rate (Figure 15). If the damping hole is overly large, an excessive amount of fluid enters the piston chamber when the piston chamber connects to the damping hole, which causes a larger flow rate amplitude. If the damping hole is too small, a larger amount of fluid enters the piston chamber when the piston chamber connects to the outlet port, which also leads to a larger flow rate amplitude.

In addition, the damping hole affects the second maximum swash plate moment (Figure 16). The second maximum swash plate moment is smaller when the radius is smaller because the rotational angle at which the pressure equals the outlet pressure is larger. The first maximum swash plate moment is larger than the second one when the radius is smaller than one, and the amplitude of the swash plate moment is nearly the same. If the radius further increases, the second maximum swash plate moment might be larger than the first one, whereas the amplitude of the swash plate moment would become larger.

\subsection{Effects of Damping Hole Three}

Figure 17 shows the effects of the radius of damping hole three, $r_{3}$, on the piston chamber pressure. The radius of the damping hole affects the rotational angle at which the piston chamber pressure starts decreasing, as well as the rotational angle at which the pressure equals the inlet pressure. The pressure starts decreasing earlier when the radius is larger, which can avoid the pressure overshoot that occurs when the radius is not sufficiently large (Figure $17(\mathrm{~b}))$. This is because when the radius is larger, the piston chamber links to the pump case earlier.

The piston chamber pressure decreases faster when the radius is larger (Figure 17(c)). This would reduce the amount of fluid entering the piston chamber from the inlet port, which reduces the flow rate amplitude in the inlet port (Figure 18). However, if the expansion process is too fast, the pressure will fall below the saturation

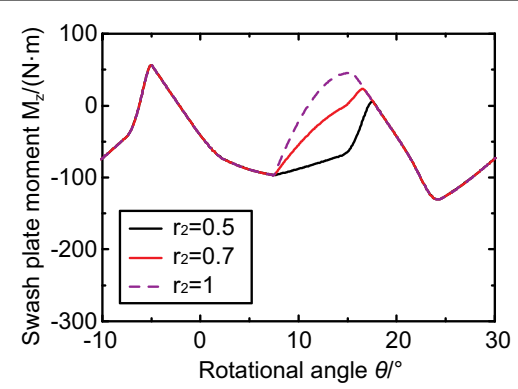

Figure 16 Effects of damping hole two on the swash plate moment

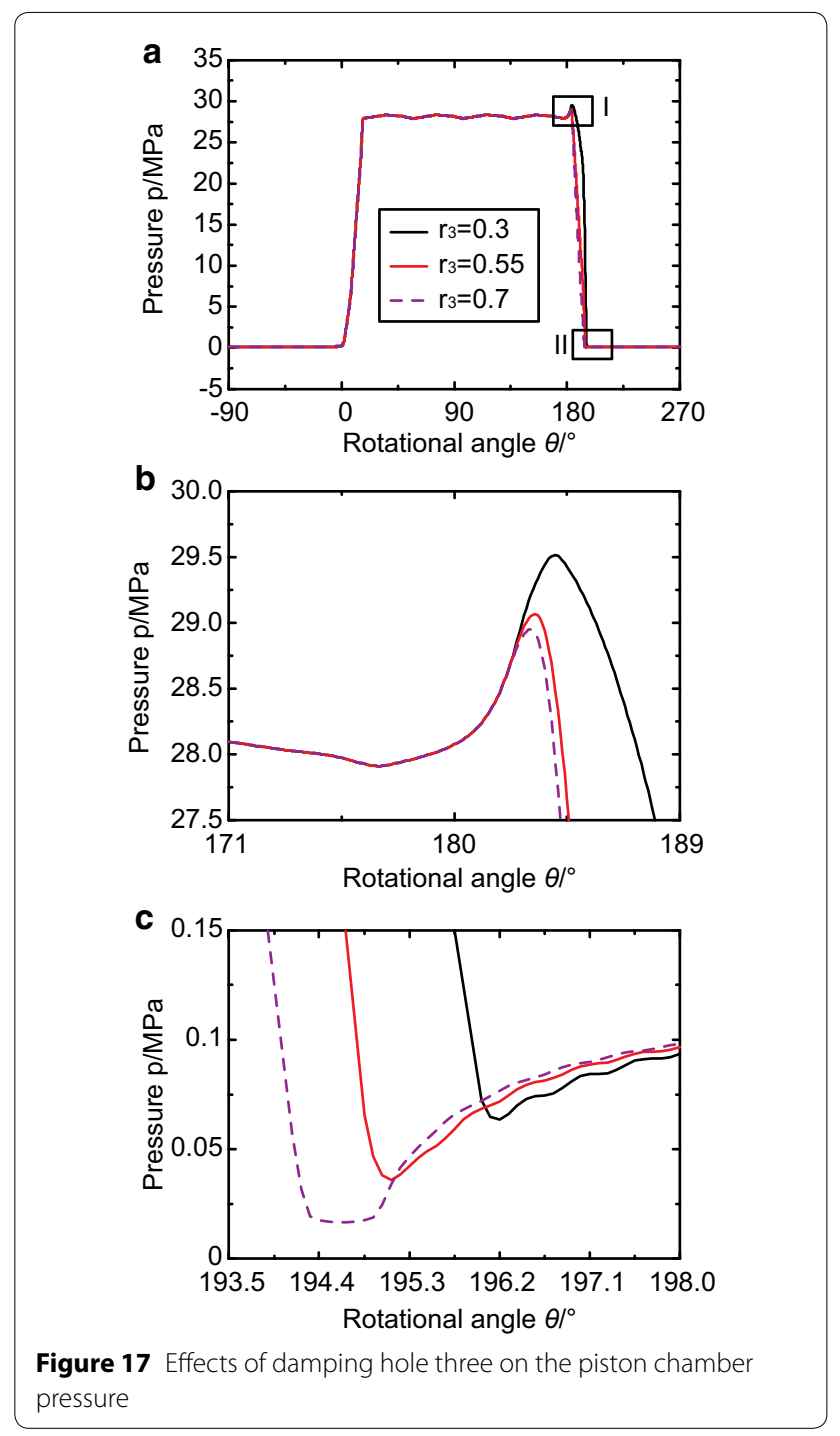

pressure because the amount of fluid from the damping hole is not sufficient to fill the increased piston chamber due to the backward motion of the piston. This will cause dissolved air release into the fluid, which leads to a bad filling performance. The fluid in the piston chamber expands earlier when the radius is larger, and the first maximum swash plate moment and second minimum swash plate moment are larger (Figure 19). Because the increase in the first maximum swash plate moment is smaller than the decrease in the second minimum one, the amplitude of the swash plate moment decreases.

Table 2 shows the minimum and maximum pressures in the piston chamber, the amplitudes of the flow rates in the inlet and outlet ports and the amplitude of the swash plate moment with different valve plate parameters. The minimum pressure is affected by $r_{1}$ and $r_{3}$, and $r_{2}$ has no effect. The maximum pressure increases with 


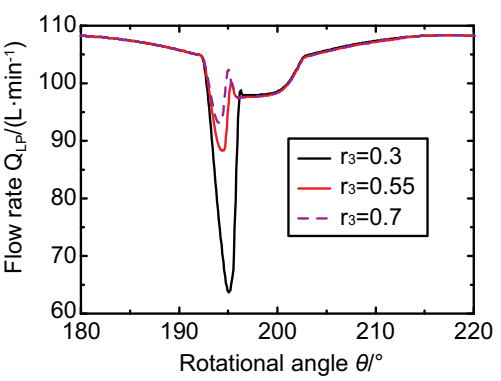

Figure 18 Effects of damping hole three on the inlet flow rate

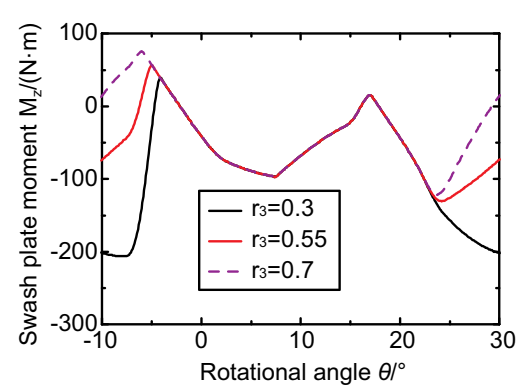

Figure 19 Effects of damping hole three on the swash plate moment

increases in $r_{2}$ and $r_{3}$, and decreases with an increase in $r_{1}$. The amplitude of the outlet flow rate decreases with increases in $r_{1}$ and $r_{2}$. This indicates that $r_{1}$ and $r_{2}$ must match each other to achieve the smallest outlet flow ripple and pressure overshoot. The amplitude of the swash plate moment decreases with an increase in $r_{1}$, and the effect of $r_{3}$ on the amplitude of the swash plate moment is not linear. $r_{2}$ has no effect on the amplitude of the swash plate moment. However, the amplitude of the swash plate moment would be affected by changes in the first maximum and the second minimum swash plate moments
(Figure 16). Thus, the swash plate moment is determined by a combination of all of these parameters. The amplitude of the inlet flow rate is mainly affected by $r_{3}$, and $r_{1}$ has a smaller effect. Thus, it is difficult to determine the optimal valve plate parameters by parametric analysis even though the ranges of the valve plate parameters can be determined from the parametric analysis to avoid undesired performance.

\section{Multi-objective Optimization}

Due to the limitations of the parametric study, an optimization methodology is required to optimize the valve plate parameters to reduce the pump noise. A multiobjective optimization genetic algorithm that accounts for both the structure-borne noise sources and fluidborne noise sources is employed.

\subsection{Definition of the Objective Functions}

At the beginning of the multi-objective optimization, objective functions must be defined properly to describe the noise characteristics. The amplitude of the swash plate moment and the flow rates in the inlet and outlet ports are chosen as the objective functions for their good representation of structure-borne noise sources and fluid-borne noise sources. There are three objective functions in total, as given by Eqs. (12)-(15):

$$
\begin{aligned}
& f_{1}(X)=\max \left(M_{z}(X)\right)-\min \left(M_{z}(X)\right) \\
& f_{2}(X)=\max \left(Q_{\mathrm{LP}}(X)\right)-\min \left(Q_{\mathrm{LP}}(X)\right) \\
& f_{3}(X)=\max \left(Q_{\mathrm{HP}}(X)\right)-\min \left(Q_{\mathrm{HP}}(X)\right) \\
& \min F(X)=\left(f_{1}(X), f_{2}(X), f_{3}(X)\right)
\end{aligned}
$$

\begin{tabular}{|c|c|c|c|c|c|c|}
\hline Parameter & Value $(\mathrm{mm})$ & $p_{\min }\left(10^{-2} \mathrm{MPa}\right)$ & $p_{\max }(\mathrm{MPa})$ & $\Delta Q_{\mathrm{LP}}(\mathrm{L} / \mathrm{min})$ & $\Delta Q_{H P}(\mathrm{~L} / \mathrm{min})$ & $\Delta M_{\mathrm{Z}}(\mathrm{Nm})$ \\
\hline \multirow[t]{4}{*}{$r_{1}$} & 0 & 1.7 & 29.81 & 20.42 & 7.34 & 282.1 \\
\hline & 0.3 & 4.7 & 29.45 & 20.26 & 5.80 & 234.9 \\
\hline & 0.55 & 4.7 & 29.12 & 20.06 & 3.51 & 186.2 \\
\hline & 0.7 & 4.7 & 28.75 & 21.31 & 3.06 & 183.3 \\
\hline \multirow[t]{3}{*}{$r_{2}$} & 0.5 & 4.7 & 29.11 & 20.06 & 4.37 & 186.2 \\
\hline & 0.7 & 4.7 & 29.12 & 20.06 & 3.51 & 186.2 \\
\hline & 1 & 4.7 & 29.14 & 20.06 & 3.90 & 186.2 \\
\hline \multirow[t]{3}{*}{$r_{3}$} & 0.3 & 7.9 & 29.51 & 44.76 & 3.51 & 244.9 \\
\hline & 0.55 & 4.7 & 29.12 & 20.06 & 3.51 & 186.2 \\
\hline & 0.7 & 3.1 & 28.95 & 15.04 & 3.51 & 197.7 \\
\hline
\end{tabular}

Table 2 Effects of damping holes on the noise sources 


\subsection{Definition of the Variables and Constraints}

The ten structural parameters listed in Table 1 are variables used for the optimization. The parameters defining the starting and ending positions of the inlet and outlet ports result in four variables. The parameters defining each damping hole are the center of the location and the radius of the damping hole. There are six variables for the three damping holes in total. The ranges of the variables are also required to allow for the manufacturing of an actual valve plate, and their values are set according to the parametric analysis. In addition, different constraints are required to provide a reasonable and realistic optimization. The pressure overshoot and undershoot are limited, for which the smallest and largest piston chamber pressures are used as constraints to avoid unexpected phenomena. The upper limit of the piston chamber pressure is $3 \mathrm{MPa}$ higher than the average outlet pressure, whereas the lower limit is $0.05 \mathrm{MPa}$ to avoid air-release and cavitation.

\subsection{Optimization Procedure}

The multi-objective genetic algorithm optimization is based on Darwin's theory of natural selection. In the optimization, an individual represents a set of parameter values. In the first step, a population of individuals is generated by the use of a pseudo-random number generator. In the second step, each individual is simulated and evaluated. The best are kept, whereas the others are removed and replaced by 'children' of the best. In addition, the parameter values are changed by adding noise to the parameters of a specific individual. The mean value of the noise is 0 . The mutation amplitude, $m_{\mathrm{a}}$, varies between 0 and 1 , and it is used to compute the standard deviation of the noise, which is given as

$$
\sigma=m_{a}\left(p a_{\text {upper }}-p a_{\text {lower }}\right)
$$

where $p a_{\text {upper }}$ and $p a_{\text {lower }}$ are the upper and lower limits of a parameter, respectively.

If the mutation amplitude is near 0 , the speed of convergence increases. If the mutation amplitude is near 1 , more time is required to obtain convergence because there are more designs to explore. After several generations, individuals converge to one or several best solutions.

The number of runs to be performed is given as

$$
N_{r}=N+N r_{p}(G-1)
$$

where $N$ is the population size, $r$ is the reproduction ratio and $G$ is the number of generations. The population size is chosen according to the number of parameters. It is typically set as a value larger than five times the number of parameters, and here, it is set as 60 because there are ten parameters. The reproduction ratio is the percentage of the population that is replaced by new individuals at each iteration, and here, it is set as the $70 \%$ recommended by experimental results. The number of generations depends on the expected calculation time, and here, it is set as 20. Thus, there are 858 runs and 858 designs after the optimization.

\subsection{Optimization Results}

Pareto-optimal solutions are obtained at the finish of the optimization as shown in Figure 20. Each triangle represents an individual design (49 out of 858). Among the designs, the amplitude of the inlet flow rate varies between 10 and $40 \mathrm{~L} / \mathrm{min}$, the amplitude of the outlet flow rate varies between 2 and $7 \mathrm{~L} / \mathrm{min}$, and the amplitude of the swash plate moment varies between 80 and $300 \mathrm{Nm}$. When the outlet flow ripple is the smallest, the inlet flow ripple is the largest, whereas when the inlet flow ripple is the smallest, the outlet flow ripple is the largest (Figure 20(a)). In addition, when the inlet flow ripple decreases, the swash plate moment increases (Figure 20(b)). Because the three objective functions are weighted equally, the optimal design is chosen as the one nearest to the origin $\left(\min \left(f_{1}(x)^{2}+f_{2}(x)^{2}+f_{3}(x)^{2}\right)^{1 / 2}\right.$ ).

The final values of the valve plate parameters are determined by rounding the optimization result, as shown in Table 1. The simulated noise sources at a wide range of pressure levels for the original and optimized valve plates are shown in Figure 21. In the simulation, the pressure in the outlet line is regulated by a pressure relief valve, which coincides with the noise measurement in

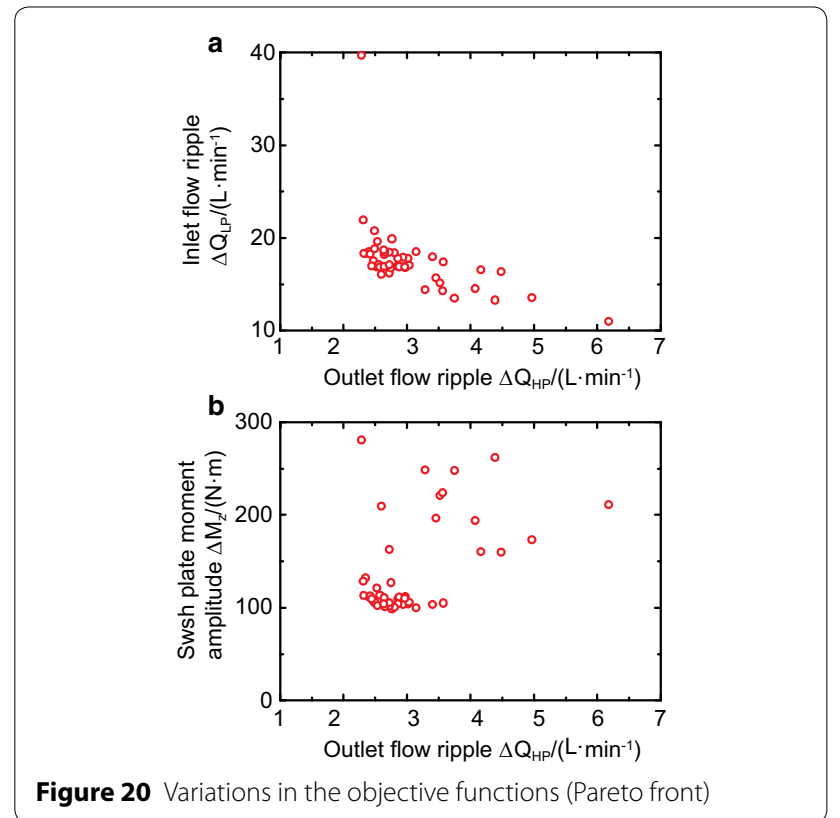



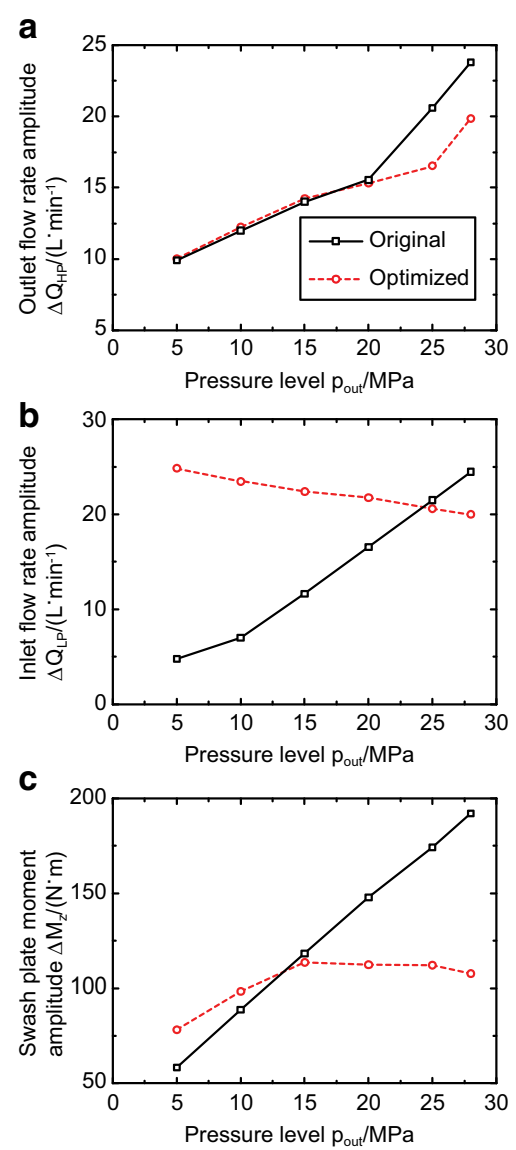

Figure 21 Simulated noise sources at different pressure levels

Section 5.5. In the optimization, the pressure in the outlet line is regulated by the throttle valve. This is because the pressure relief valve would affect the dynamics in the outlet line by varying the opening of the pressure relief valve to maintain a constant outlet pressure, whereas the dynamics are not affected by using the throttle valve. Therefore, the flow rates in the outlet and inlet are different when different methods are used to load the system.

As shown in Figure 21(a), the amplitudes of the outlet flow rates are reduced when the pressure levels are larger than $15 \mathrm{MPa}$, and the amplitudes are nearly the same when the pressure levels are smaller than $15 \mathrm{MPa}$. The amplitudes of the inlet flow rates are reduced at 25 and $28 \mathrm{MPa}$, and the values increase as the pressure level gets smaller. The amplitude of the swash plate moment is reduced when the pressure level is higher than $10 \mathrm{MPa}$, and the values increase at 5 and $10 \mathrm{MPa}$. The main cause of the larger noise sources is that the optimization is carried out at the rated operating condition $(28 \mathrm{MPa})$, and the optimal results obtained at this operating condition cannot reduce the noise sources at lower pressure levels. However, because the investigated pump is designated to be used at a high pressure, the increase in noise sources at low pressures is acceptable.

\subsection{Noise Measurement}

The noise of the pump with the original and optimized valve plates was measured in a hemi-anechoic chamber built according to the requirements of ISO 4412-1 [30], as shown in Figure 22. The interior clear dimensions of the hemi-anechoic chamber are $5.1 \times 4.4 \times 2.6 \mathrm{~m}^{3}$ (length, width and height) with a minimum background noise of $11.4 \mathrm{~dB}$ and a lowest measurable frequency of $25 \mathrm{~Hz}$. The test arrangement keeps the pump placed at the center of the reflecting plane. The pump mounting and drive shaft support bearing are mounted on massive concrete blocks to structurally isolate them from the floor to prevent vibrations from exciting the entire building.

The inlet, outlet and leakage lines are all flexible hoses. The shortage is that no acoustic cladding has been done to them, and no acoustic cladding has been done to the shaft support either. This allows the noise emitted from these components to reach the microphones as well. However, the noise emitted from these components is smaller than that emitted by the pump, and the measured sound pressure level can be regarded as the sound pressure level emitted from the pump.

The positions of the microphones were defined according to ISO 3745-2003 [31], assuming that there is one reflecting plane in the sound-free field. As there are only five microphones available, and the sound power level (SWL) was calculated by averaging the sound pressure level (SPL) at ten microphone positions, the microphone positions were moved manually during the measurement. The measurement of SWL was divided into two steps. The first step was to measure the SPL at the first five microphone positions, and the second step was to measure the SPL at the other five microphone positions.

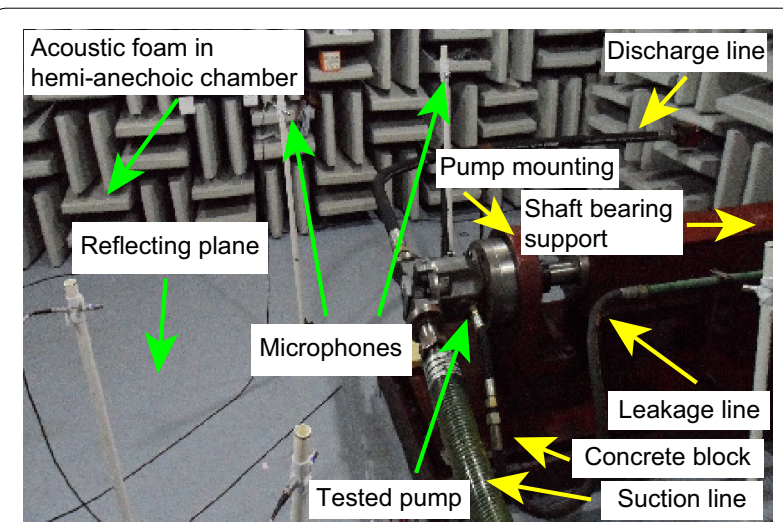

Figure 22 The tested pump in a hemi-anechoic chamber 
The microphones are type 4189-A-021 (Brüel \& Kjær) with an error of $0.2 \mathrm{~dB}$ and a measurable frequency ranging from 6-20000 Hz. The signal acquisition equipment is PULSE LAN-XI 3050-A-060 with six channels. All microphones were calibrated with a B\&K type 4231 sound calibrator.

The hydraulic system used to drive the pump is situated in another room to eliminate the effects of their noise on reducing the measurement accuracy. The hydraulic system is shown in Figure 23, with the specifications listed in Table 3. The pump is driven by an electrical motor, and the pressure in the outlet line is regulated by a pressure relief valve. A cardan shaft is used to transmit the torque to the pump with a hook joint at the motor end and a coupling at the pump end.

Figure 24 shows the sound pressure levels from the axial piston pump with the original and optimized valve plates at the speed of $1500 \mathrm{r} / \mathrm{min}$ and the maximum displacement. The noise level increases with an increase of pressure level. The noise level of the optimized design is higher at the pressure levels of 5 and $10 \mathrm{MPa}$. This result coincides with the increases of noise sources at low pressure levels (Figure 21). The optimized design is quieter than the original design when the measured pressure levels are larger than $15 \mathrm{MPa}$, and the noise level at the rated pressure is reduced from $80.7 \mathrm{~dB}(\mathrm{~A})$ to $79.1 \mathrm{~dB}(\mathrm{~A})$.

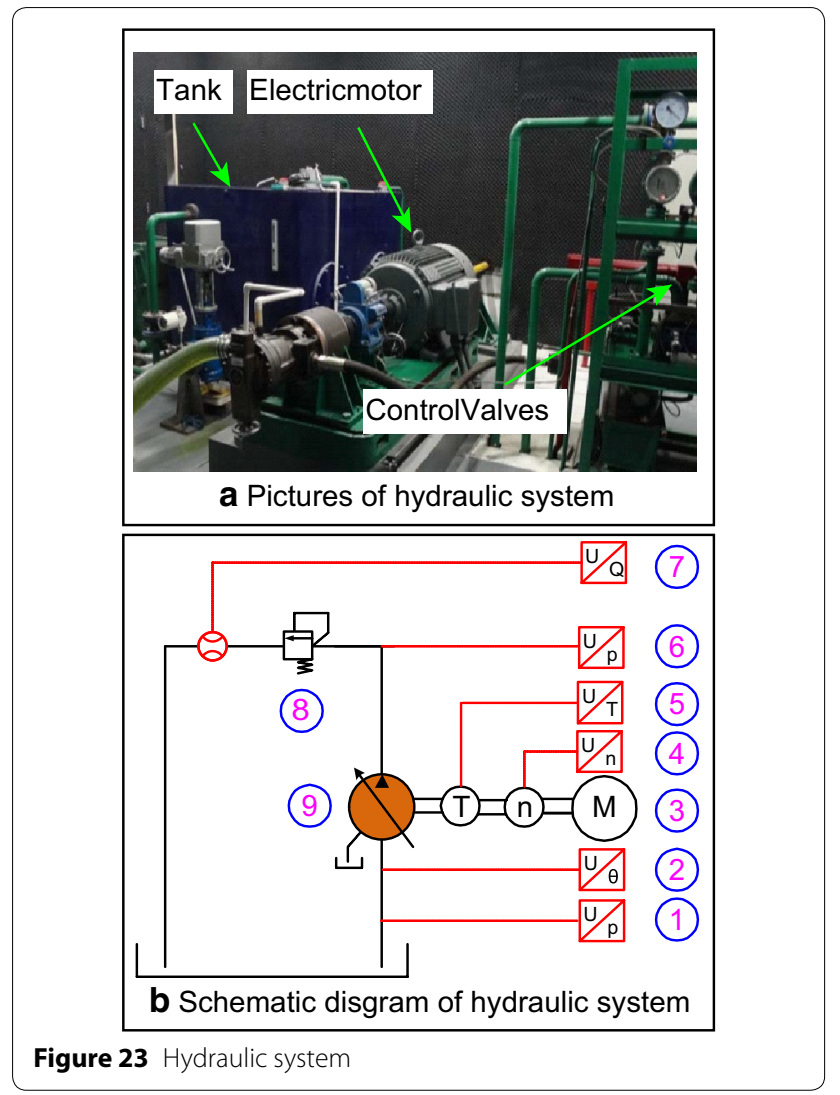

Table 3 Details of the hydraulics system

\begin{tabular}{|c|c|c|}
\hline No. & Description & Detail \\
\hline 1 & Inlet pressure sensor & NS-11, 0-1 MPa, accuracy 0.3\% FS \\
\hline 2 & Inlet temperature sensor & $\begin{array}{l}\text { SBWR/Z, range }-25-120^{\circ} \mathrm{C} \text {, accuracy } \\
0.25 \% \mathrm{FS}\end{array}$ \\
\hline 3 & Electric motor & Y315L2-2, speed range $300-2980 \mathrm{r} / \mathrm{min}$ \\
\hline 4 & Shaft speed sensor & $\begin{array}{l}J C 2 C \text {, range } 0-4000 \mathrm{r} / \mathrm{min} \text {, accuracy } \pm 1 \\
\mathrm{r} / \mathrm{min}\end{array}$ \\
\hline 5 & Shaft torque sensor & $\begin{array}{l}\text { JC2C, range } 0-2000 \mathrm{Nm}, 0.2 \text { class } \\
\text { accuracy }\end{array}$ \\
\hline 6 & Outlet pressure sensor & $\mathrm{NSI}$, range $0-40 \mathrm{MPa}$, accuracy $0.3 \% \mathrm{FS}$ \\
\hline 7 & Outlet flow meter & $\begin{array}{l}\text { LC-A50, range } 0-400 \mathrm{~L} / \mathrm{min}, 0.2 \text { class } \\
\text { accuracy }\end{array}$ \\
\hline 8 & Pressure relief valve & DBDH6P1X400 \\
\hline 9 & Test pump & $71 \mathrm{cc} / \mathrm{rev}$ \\
\hline
\end{tabular}

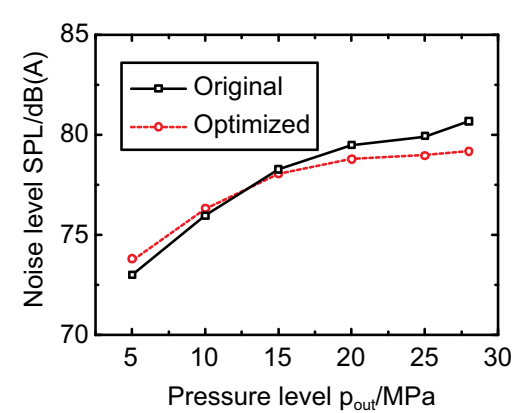

Figure 24 Measured sound pressure level for the original and optimized pump

\section{Conclusions}

(1) The pump model with carefully modeled fluid property is effective in analyzing the phenomena of airrelease and cavitation. The noise of an axial piston pump is affected by the inlet and outlet flow ripples, and the pulsation of swash plate moment.

(2) Valve plate parameters have great impacts on the generation of noise sources, both fluid-borne noise and structure-borne noise sources. A multi-objective optimization method is required to find the best valve plate parameters in order to reduce all the noise sources. The objective functions and constraints used in the optimization are adequate.

(3) The noise sources and the noise levels are reduced at high pressure levels by a comparison between the original and optimized valve plates, and the noise is reduced by $1.6 \mathrm{~dB}(\mathrm{~A})$ at the rated pressure level.

(4) The optimization method is effective in optimizing the valve plate parameters to reduce the noise levels. The valve plate used in this study can also be 
applied to other kinds of axial piston pumps, and the method used here can be extended to other kinds of axial piston machines.

\section{Authors' Contributions}

BX was in charge of the whole trial; S-GY and J-HZ wrote the manuscript; S-GY and $\mathrm{J}-\mathrm{HZ}$ assisted with sampling and laboratory analyses. All authors read and approved the final manuscript.

\section{Author details}

1 State Key Laboratory of Fluid Power and Mechatronics Systems, Zhejiang University, Hangzhou 310027, China. ${ }^{2}$ Ocean College, Zhejiang University, Zhoushan 316021, China.

\section{Authors' Information}

Shao-Gan Ye, born in 1989, is currently a post-doctorial at Ocean College, Zhejiang University, China. His main research interest is noise control of axial piston machines

Jun-Hui Zhang, born in 1983, is currently a research associate at State Key Laboratory of Fluid Power Transmission and Control, Zhejiang University, China. His main research interests are fluid power transmission and control, and noise control of axial piston machines

Bing Xu, born in 1971, is currently a professor and a PhD candidate supervisor at State Key Laboratory of Fluid Power Transmission and Control, Zhejiang University, China. His main research interests are fluid power transmission and control, and noise control of axial piston machines.

\section{Acknowledgements}

The authors would like to express their appreciation to Professor Su-Mei Chen in Fuzhou University for providing the necessary assistant during the measurements of sound pressure levels.

\section{Competing Interests}

The authors declare no competing financial interests.

\section{Funding}

Supported by National Basic Research Program of China (Grant No. 2014CB046403), and Zhejiang Provincial Natural Science Foundation of China (Grant No. LQ14E050005)

\section{Publisher's Note}

Springer Nature remains neutral with regard to jurisdictional claims in published maps and institutional affiliations.

Received: 16 October 2017 Accepted: 22 June 2018

Published online: 05 July 2018

\section{References}

[1] T Nafz, H Murrenhoff, R Rudik. Noise reduction of hydraulic systems by axial piston pumps with variable reversing valves. Proceedings of the 8 th International Fluid Power Conference, Dresden, Germany, 2012: 1-12.

[2] Bin Zhang, Bing Xu, Chun-Lin Xia, et al. Modeling and simulation on axial piston pump based on virtual prototype technology. Chinese Journal of Mechanical Engineering, 2009, 22(1): 84-90.

[3] Ji-En Ma, Bing Xu, Bin Zhang, et al. Study on flow ripple of axial piston pump with CFD simulation using compressible fluid oil. Chinese Journal of Mechanical Engineering, 2010, 23(1): 45-52.

[4] Bing Xu, Yue-Chao Song, Hua-Yong Yang. Pre-compression volume on flow ripple reduction of a piston pump. Chinese Journal of Mechanical Engineering, 2013, 26(6): 1259-1266.

[5] L Ericson. On fluid power pump and motor design - tools for noise reduction. Linköping, Sweden: Linköping University, 2011.

[6] K A Edge, J Darling. The pumping dynamics of swash plate piston pumps. Journal of Dynamic Systems, Measurement, and Control, 1989, 111(2): 307-312.
[7] N D Manring. Valve-plate design for an axial piston pump operating at low displacements. Journal of Mechanical Design - Transactions of the ASME, 2003, 125(1): 200-205.

[8] N P Mandal, R Saha, D Sanyal. Theoretical simulation of ripples for different leading-side groove volumes. Proceedings of the Institution of Mechanical Engineers, Part l: Journal of Systems and Control Engineering, 2008, 222(6): 557-570

[9] N P Mandal, R Saha, D Sanyal. Effects of flow inertia modelling and valveplate geometry on swash-plate axial-piston pump performance. Proceedings of the Institution of Mechanical Engineers, Part l: Journal of Systems and Control Engineering, 2011, 226(4): 451-466.

[10] G K Seeniraj, M Ivanysynova. Noise reduction in axial piston machines based on multi-parameter optimization. Proceedings of the 4th FPNI, Sarasota, Florida, USA, June 13-17, 2006: 235-246.

[11] M Ivantysynova, G K Seeniraj. Impact of valve plate design on noise, volumetric efficiency and control effort in an axial piston pump. Proceedings of ASME 2006 International Mechanical Engineering Congress and Exposition, Chicago, Illinois, USA, November 5-10, 2006: 77-84.

[12] G K Seeniraj, M Ivanysynova. Noise reduction in axial piston machines based on multi-parameter optimization. Proceedings of the 5th FPNI PhD Symposium, Cracow, Poland, June 1-5, 2008: 1-10.

[13] G K Seeniraj, M Ivanysynova. Multi-objective optimization tool for noise reduction in axial piston machines. Proceedings of SAE International Commercial Vehicle Engineering Congress \& Exhibition, Rosemont, Illinois, USA, October 7-9, 2008: 544-552.

[14] G K Seeniraj, M Ivanysynova. A multi-parameter multi-objective approach to reduce pump noise generation. International Journal of Fluid Power, 2011, 12(1): 7-17.

[15] Jia-Hai Huang, Hu Zhao, Long Quan, et al. Development of an asymmetric axial piston pump for displacement-controlled system. Proceedings of the Institution of Mechanical Engineers, Part C: Journal of Mechanical Engineering Science, 2014, 228(8): 1418-1430.

[16] Jia-Hai Huang, Long Quan, Xiao-Gang Zhang. Development of a dualacting axial piston pump for displacement-controlled system. Proceedings of the Institution of Mechanical Engineers, Part B: Journal of Engineering Manufacture, 2014, 228(4): 606-616.

[17] A Johansson, J O Palmberg. The importance of suction port timing in axial piston pumps. Proceedings of The 9th Scandinavian International Conference on Fluid Power, Linköping, Sweden, June 1-3, 2005: 184-198.

[18] J M Bergada, S Kumar, D L Davies, et al. A complete analysis of axial piston pump leakage and output flow ripples. Applied Mathematical Modelling, 2012, 36(4): 1731-1751

[19] M Pelosi, M Ivantysynova. Heat transfer and thermal elastic deformation analysis on the piston/cylinder interface of axial piston machines. Journal of Tribology, 2012, 134(4): 1-15.

[20] Bing Xu, Jun-Hui Zhang, Hua-Yong Yang, et al. Investigation on the radial micro-motion about piston of axial piston pump. Chinese Journal of Mechanical Engineering, 2013, 26(2): 325-333.

[21] J M Bergada, J M Haynes, J Watton. Leakage and groove pressure of an axial piston pump slipper with multiple lands. Tribology Transactions, 2008, 51(4): 469-482.

[22] J M Bergada, J Watton, J M Haynes. The hydrostatic/hydrodynamic behaviour of an axial piston pump slipper with multiple lands. Meccanica, 2010, 45(4): 585-602.

[23] J M Bergada, J Watton, S Kumar. Pressure flow, force and torque between the barrel and port plate in an axial piston pump. Journal of Dynamic Systems Measurement and Control, 2008, 130(1): 1-16.

[24] Bing Xu, Jun-Hui Zhang, Hua-Yong Yang. Simulation research on distribution method of axial piston pump utilizing pressure equalization mechanism. Proceedings of the Institution of Mechanical Engineers, Part C: Journal of Mechanical Engineering Science, 2013, 227(3): 459-469.

[25] Chang-Bin Guan, Zong-Xia Jiao, Shou-Zhan He. Theoretical study of flow ripple for an aviation axial-piston pump with damping holes in the valve plate. Chinese Journal of Aeronautics, 2014, 27(1): 169-181.

[26] J Ivantysyn, M Ivantysynova. Hydrostatic pumps and motors: principles, design, performance, modelling, analysis, control and testing. New Delhi, India: Tech Books International, 2003.

[27] P Casoli, A Vacca, G Franzoni, et al. Modelling of fluid properties in hydraulic positive displacement machines. Simulation Modelling Practice and Theory, 2006, 14(1): 1059-1072. 
[28] A Vacca, R Klop, M Ivantysynova. A numerical approach for the evaluation of the effects of air release and vapour cavitation on effective flow rate of axial piston machines. International Journal of Fluid Power, 2010, 11(1): 33-45.

[29] S A Imagine. HYD advanced fluid properties. Technical bulletin n 117. 2007

[30] The International Organization for Standardization. ISO 4412-1:1991,

Hydraulic fluid power - Test code for determination of airborne noise levels Part 1: Pumps. London: British Standards Institution, 1991.
[31] The International Organization for Standardization. ISO 3745: 2012, Acoustics - Determination of sound power levels and sound energy levels of noise sources using sound pressure - Precision methods for anechoic rooms and hemi-anechoic rooms. London: British Standards Institution, 2012.

\section{Submit your manuscript to a SpringerOpen ${ }^{\circ}$ journal and benefit from:}

- Convenient online submission

- Rigorous peer review

- Open access: articles freely available online

- High visibility within the field

- Retaining the copyright to your article

Submit your next manuscript at $\boldsymbol{\nabla}$ springeropen.com 